\title{
Tabaco y desarrollo económico en Santo Domingo (siglo XVIII)
}

\section{Antonio Gutiérrez Escudero}

Escuela de Estudios Hispano-Americanos, CSIC. Sevilla

A mediados del siglo XVIII el estanco del tabaco suponía una importante fuente de recursos para la Corona, de ahí el interés por su implantación en todos los territorios americanos posibles. Con este fin, en 1763 se creaba una factoría en Santo Domingo dada la excelente calidad del tabaco dominicano. Sobre ambos temas en el presente artículo se realiza un análisis de sus antecedentes, génesis y desarrollo, se relaciona una serie de ingresos y gastos derivados del funcionamiento de la factoría y se incluye un apéndice documental como un ejemplo de las partidas de tabaco adquiridas a los cosecheros para su embarque a la Península.

La historia del tabaco dominicano ${ }^{1}$ durante la etapa colonial se compone de una serie de noticias esporádicas o muy concretas recogidas en estudios de economía más amplios ${ }^{2}$ y algún que otro aporte particular sobre el tema. ${ }^{3}$ Y eso que el término "tabaco" aparece usado como tal, en la isla Española, en la fecha temprana de 1529 y que desde esta tierra americana nos llegó una de las primeras crónicas sobre la planta y el uso que de ella hacían los europeos; así Las Casas afirma que "españoles conocí yo en esta isla Española que los acostumbran tomar [el tabaco], que siendo reprendidos por ello, diciéndoles que aquello era vicio, respondían que no era de su mano dejarlos; no sé qué sabor o provecho hallaban en ello". ${ }^{4}$

1 Este trabajo es parte de los resultados del Proyecto PB98-0686 ("Instituciones mercantiles y hombres de negocios en España y América: relaciones, influencias y dependencias") financiado por el MEC. Una primera versión fue presentada al XII Congreso de Historia de América de AHILA, celebrado en Oporto en septiembre de 1999.

2 Véanse a este respecto las obras de Cassá, Roberto: Historia social y económica de la República Dominicana. Santo Domingo, 1985, tomo I; Gutiérrez Escudero, Antonio: Población y economía en Santo Domingo, 1700-1746. Sevilla, 1985, págs. 108-113; Moya Pons, Frank: Historia colonial de Santo Domingo. Santiago (Rep. Dominicana), 1974 y Sevilla Soler, Rosario: Santo Domingo Tierra de frontera (1750-1800). Sevilla, 1981, págs. 104-117.

3 Véase Lluberes Navarro, Antonio, "Tabaco y catalanes en Santo Domingo durante el siglo XVIII", EME EME, vol. V, núm. 28, Santiago (Rep. Dominicana), enero-febrero de 1977, págs. 13-26. Yo mismo he escrito dos artículos sobre el tema: Gutiérrez Escudero, A.: "Tabaco y algodón en Santo Domingo, 1731-1795", en Sarabia, Justina y otros: Entre Puebla de los Ángeles y Sevilla. Sevilla, 1987, págs. 151-169 y "El tabaco en Santo Domingo y su exportación a Sevilla (época colonial)", en E. Vila y A. Kuethe: Relaciones de poder y comercio colonial. Sevilla, 1999, págs. 117-142.

4 Las Casas, fray Bartolomé de: Historia de las Indias, libro I, capítulo 46, citado por Céspedes del Castillo, Guillermo: El tabaco en Nueva España. Madrid, 1992, pág. 27. 
Del mismo modo ya se ha puesto de manifiesto que a Sevilla debieron llegar las primeras simientes de tabaco cuando el siglo XV tocaba a su fin, que el médico Nicolás Monardes consiguió aclimatar y sembrar la planta en el jardín botánico de su casa en la ciudad hispalense, y que esta capital se convertiría en "el primer centro manufacturero de importancia en el país, o incluso en el Viejo Mundo". ${ }^{5}$

Con este trabajo pretendemos dar otro paso más en la investigación que hace tiempo llevamos a cabo sobre la importancia del cultivo del tabaco para la economía dominicana y los beneficios que de su exportación a la Real Fábrica de Sevilla se derivaron para la parte española de la isla. Al mismo tiempo, y como hemos hecho en anteriores artículos sobre esta materia, incluimos un apéndice documental que permita conocer uno de los diversos tipos de fuente que podemos encontrar a la hora de abordar el estudio de este importante producto americano, tal como el profesor Céspedes del Castillo ha señalado oportunamente. ${ }^{6}$

Es sabido que en fecha cercana al siglo XVIII únicamente se cosechaba el tabaco preciso para el gasto particular de los habitantes de la isla, como diversas fuentes así lo confirman: en 1699 el oidor Araujo y Rivera ${ }^{7}$ decía respecto del tabaco que "se cría con gran fertilidad y de buena calidad, de forma que si hubiera comercio se pudiera cultivar mucho, y por falta de él se beneficia solo el que es necesario para el consumo de la tierra".

Sin embargo está fuera de dudas que el campo dominicano - en especial las tierras de Santiago de los Caballeros y las zonas próximas- reunía la condiciones óptimas para que se sembrara "de tabaco, especie que se da allí con muchas ventajas a toda la América, así en la calidad como en la abundancia y tamaño de la hoja". ${ }^{8}$ Y que la ocupación francesa de la región occidental de la isla y el espectacular desarrollo económico de la misma a partir del

5 Rodríguez Gordillo, José Manuel: "La Real Fábrica de tabacos", en VV.AA.: La Sevilla de las Luces. Sevilla, 1991, pág. 154. Véase también del mismo autor "El tabaco: del uso medicinal a la industrialización", en Fernández, J. e Ignacio González: Catálogo de la Exposición de la Agricultura viajera. Madrid, 1990, págs. 53-81.

6 Céspedes del Castillo, El tabaco, pág. 13.

7 "Descripción de la isla Española o de Santo Domingo" por Fernando Araujo y Rivera, en Rodríguez Demorizi, Emilio: Relaciones históricas de Santo Domingo. Santo Domingo, 1945, vol. I, pág. 302. pág. 185 .

8 Sánchez Valverde, Antonio: Idea del valor de la isla Española. Santo Domingo, 1976, 
Tratado de Ryswick (1697) ${ }^{9}$ era un ejemplo incuestionable de las verdaderas posibilidades de progreso de la parte hispana, que además contaba con la ventaja de disponer de mayor espacio territorial para la expansión agrícola.

Es ya en pleno siglo XVIII, con la implantación del reformismo borbónico, cuando la historia del tabaco dominicano contemplará un cambio fundamental, en especial porque el propio gobierno metropolitano se percatará de que el cultivo y comercialización de la planta podría suponer una importante fuente de recursos para la reconstrucción del poder imperial y una renta a la que, por tanto, no se debía renunciar. ${ }^{10}$

En este motivo anterior radica la causa principal que favorece la continua aparición de proyectos sobre la mejora y potenciación de los cultivos de tabaco, la instalación de molinos de agua, ${ }^{11}$ las recomendaciones de incremento de superficies para cultivar la planta, ${ }^{12}$ los informes sobre la excelencia del tabaco dominicano, de "tan buena y de mejor calidad que el de aquella isla [Cuba], y con la gran excusa de no tener aquí salida este fruto, no se aplican a sembrarlo ni a beneficiar más que el preciso para su propio consumo, del que se les pierde mucho por su excesivo rendimiento", ${ }^{13}$ o los frecuentes envíos de cargas de tabaco a la Península. ${ }^{14}$

Pero creemos que el gran hándicap del tabaco dominicano fue la mejor consideración que siempre mantuvo el tabaco cubano. De modo que tuvieron que suceder varios hechos fortuitos para que la situación cambiara sustancialmente. Entre ellos señalemos la ocupación de La Habana por los ingleses en 1762 y la interrupción del envío de tabaco cubano a Sevilla — si bien es cierto, como se ha afirmado recientemente, que la Real Fábrica disponía de otras posibilidades de abastecimiento. ${ }^{15}$

9 Para esta materia véase Gutiérrez Escudero, Antonio: "Cuestión de límites en la isla Española, 1690-1777”, Temas Americanistas, núm. 1, Sevilla, 1982, págs. 22-24, y "Tres fuentes sobre Saint Domingue, 1699-1731”, Historiografía y Bibliografía Americanistas, vol. XXIV, Sevilla, 1980, págs. 23-78.

10 Navarro García, Luis, "La política indiana", en América en el siglo XVIII. Los primeros Borbones, Tomo XI-1 de la Historia General de España y América, Madrid, Rialp, 1983, págs. 22-24.

11 Archivo General de Indias, Sevilla (en adelante AGI), Santo Domingo, 303. Juan López de Morla al rey. Santo Domingo, 9 de noviembre de 1724.

12 AGI, Santo Domingo, 941. Gobernador Castro al rey. Santo Domingo, 12 de diciembre de 1733. Por su parte el gobernador Azlor informaba que "obedeciendo la real orden de 18 de octubre de 1770 fomenta las siembras de tabaco en la isla". AGI, Santo Domingo, 1.055. Azlor al rey. Santo Domingo 24 de enero de 1771.

13 AGI, Santo Domingo, 262. Castro al rey. Santo Domingo, 13 de octubre de 1735.

14 AGI, Indiferente, 1.745. Gobernador Azlor al rey. Santo Domingo, seis de febrero de 1763.

15 Véase Rodríguez Gordillo, José M.: "El abastecimiento de tabacos en el marco del estanco español en el siglo XVIII: reflexiones previas para su estudio”, en González Enciso, Agustín y Rafael Torres Sánchez (editores): Tabaco y economía en el siglo XVIII. Pamplona, 1999, págs. 239-270. 
Por ese motivo debemos añadir al menos otros dos factores coadyuvantes al proceso antes citado. En primer lugar, una crisis en la producción de tabaco cubano cuya cantidad y, sobre todo, su calidad mermó bastante. Así, por ejemplo, se emitieron varios informes de los expertos de la Real Fábrica hispalense acerca de la excelencia del tabaco dominicano, equiparable en todo e incluso superior, se dice, a la mejor hoja habanera, pues la procedente "del partido de Licey de primera calidad, distinguida en la factura con L.P. y L., y la del mismo partido de segunda calidad, señalada con R.P., excede en bondad a las que de algún tiempo a esta parte se han recibido de La Habana, y todas son a propósito para la labor de cigarros". ${ }^{16}$

En segundo lugar, debemos tener en cuenta, además, que muchos cosecheros cubanos, a consecuencia de los bajos precios de venta oficial de la hoja, habían abandonado los cultivos tabaqueros "dedicándose al plantío de cañas de azúcar, en que consiguen mayor interés, y otros han minorado mucho las labores que son precisas a la planta del tabaco para que se críe de buena calidad". ${ }^{17}$

Nace así, por Real Orden de 12 de octubre de 1763, la factoría de tabaco de Santo Domingo ${ }^{18}$ quien debía encargarse de enviar a la Real Fábrica de Sevilla el tabaco necesario para completar los dos millones de libras que ésta precisaba para sus labores habituales y que fueran de "las calidades que son más a propósito para la fábrica de cigarros".${ }^{19}$ La materia prima principal debería provenir del Cibao - región "importante a causa de las condiciones climáticas y de terreno favorables para la pequeña agricultura" y para el cultivo de la planta -20 y especialmente de la jurisdicción de Santiago. Incluso se ordenó al virrey de México que remitiese a la isla personas experimentadas que fomentasen las sementeras e instruyesen a los labradores acerca del método más beneficioso para la producción de tabaco y su manipulación. ${ }^{21}$

Por un informe del gobernador sabemos que la siembra de tabaco se hacía casi exclusivamente en Santiago de los Caballeros, donde 247 veci-

16 AGI, Santo Domingo, 1.055. Informes dados en Sevilla a 24 de octubre de 1771 y 18 de agosto de 1774. La cursiva es mía.

17 Navarro García, Luis: La política americana de Gálvez según su "Discurso y reflexiones de un vasallo". Málaga, 1998, págs. 63-64 (nota 15) y 148.

18 Véase AGI, Santo Domingo, 1.055.

19 AGI, Santo Domingo, 1.055 . Véase el punto $6 .^{\circ}$ de las Instrucciones para el factor y contador-interventor de la factoría de tabacos de Santo Domingo. San Lorenzo, 11 de octubre de 1763.

20 Cassá, Historia social y económica, tomo I, pág. 121.

21 Arcila Farias, Eduardo: El siglo ilustrado en América. Caracas, 1955, pág. 211. 
nos se ocupaban de las labores ayudados por 202 esclavos. Al cabo de un año se recogían unas diez mil arrobas, que se empleaban para el consumo interno o se comercializaban en otros puertos hispanoamericanos. Esta última práctica será ahora prohibida con objeto de aumentar la producción y los envíos hacia la Península. ${ }^{22}$

La factoría dominicana, no obstante, tuvo una vida llena de incidentes cuyos sucesos más significativos exponemos a continuación. Por ejemplo, dos años después de crearse la factoría, el gobernador Azlor mostraba su extrañeza de que mientras que el virrey de México le avisaba de la remisión de 25.000 pesos para la compra de tabacos, él "se hallaba sin instrucción ni orden alguna" para tal asunto. ${ }^{23}$ De todas formas, la irregularidad caracterizó la llegada de esos fondos asignados por el Gobierno metropolitano para la puesta en explotación de plantaciones y la adquisición de la materia prima a los cosecheros a través del situado procedente de Nueva España. ${ }^{24}$ En este sentido el gobernador Solano ya se quejaba en 1773 de que el virrey novohispano no sólo le había enviado menos caudal del estipulado para tales fines, sino que tampoco se les remitieron los atrasos correspondientes a años anteriores..$^{25}$

Y especialmente problemático fue todo lo concerniente al nombramiento de los sujetos que debían asumir los principales puestos ejecutivos de la propia factoría.

Parece que, al igual que sucedió en otros territorios hispanoamericanos, fueron elegidos dos empleados de la Real Fábrica de Sevilla, ${ }^{26}$ con cuya experiencia se contaba para poner en funcionamiento en Santo Domingo toda la infraestructura de esta importante empresa. Así al menos se hace constar en el punto octavo de las instrucciones dictadas en 1763, donde se especifica que el factor "por su antigua práctica en las Reales Fábricas se halla instruido de la perfecta construcción de cigarros y conocimiento de la hoja más aparente para asegurar la perfección de ellos y su mejor consumo con agrado de los aficionados". ${ }^{27}$

22 AGI, Santo Domingo, 1.055. Azlor al rey. Santo Domingo, 28 de junio de 1770.

23 AGI, Indiferente, 1.745. Azlor a Arriaga. Santo Domingo, 16 de noviembre de 1765.

24 AGI, Santo Domingo, 1.044. Informe de la Real Hacienda (1773).

25 AGI, Indiferente, 1.745. Solano al rey. Santo Domingo, 24 de julio de 1773.

26 En México se constata la presencia de Silvestre Díaz de la Vega, "antiguo empleado de la fábrica de Sevilla y a la sazón contador de la Renta de Nueva España, burócrata del monopolio y también un técnico en asuntos de fabricación". Céspedes, El tabaco, págs. 63-64.

27 AGI, Santo Domingo, 1.055. Instrucciones para el factor y el contador, cit. Las Instrucciones están transcritas en Gutiérrez Escudero, “Tabaco y algodón”, págs. 165-169.. 
Tal como ocurrió en otras ocasiones con todo lo relativo a la industria del tabaco, se solicitó que los sueldos asignados al factor (treinta mil reales) y al contador (doce mil reales) de la factoría de Santo Domingo se equiparasen con las retribuciones establecidas para los mismos empleos en La Habana. Aparte de que con ello se estimulaba a los individuos en el desempeño de su labor, se añadía como razón principal para esta igualdad de salarios que: "la isla de Santo Domingo es la Galicia de las Indias, y que todos los géneros, y aún muchos comestibles están por precios crecidísimos, que es imposible subvenir a los gastos con los limitados sueldos que se asignaron...pues aunque sean de plata se verán precisados a contraer empeños para mantenerse con la regular decencia que pide el carácter de los empleos y confianza, mayormente cuando se verán precisados a practicar viajes a lo interior de la isla para tomar conocimiento del país y parajes en que convenga poner mayor aplicación a los cultivos. También es digno de reflexión la precisión que tienen de tratar y conferenciar con el gobernador, audiencia y otros ministros, para que se presenten con la modesta decencia que corresponde al ser comisionados del rey". ${ }^{28}$

Es curiosa la comparación de Santo Domingo con Galicia en cuanto a la carestía de vida, pues incide en un problema sustancial: las escasas relaciones comerciales de la parte española de la isla con la Península, rasgo característico de la economía hispanodominicana a lo largo de todo el siglo $\mathrm{XVIII} .{ }^{29} \mathrm{Y}$ ni siquiera quedaba el recurso de solicitar las mercancías precisas a otras provincias indianas, pues como ya se había informado hacía tiempo "a más de que a ninguna le sobra...son tal altos los precios en ellas que habiéndose de revender en ésta con correspondiente ganancia, era menester mucha riqueza para que estos pobres comprasen lo necesario". ${ }^{30}$ En este sentido se abogó por conceder las máximas facilidades a la factoría dominicana hasta su consolidación definitiva y se formuló toda una extensa serie de medidas encaminada a incrementar los envíos de tabaco a Sevilla. Entre otras propuestas, y tal como gozaban los franceses e ingleses en sus colonias, para el trabajo en las plantaciones tabaqueras se sugirió favorecer la entrada de esclavos negros, cuyo exiguo número en las posesiones hispanas se debía a que su precio estaba incrementado por "el gravamen de un derecho excesivo, del que será conveniente exonerarles a

28 AGI, Santo Domingo, 1.055. Informe de José de Losada. Sevilla, 24 de abril de 1768. La cursiva es mía.

29 Véase AGI, Santo Domingo, 284. Cabildo de Santo Domingo al rey, 13 de abril de 1726.

30 AGI, Santo Domingo, 305. Castro al rey. Santo Domingo, 22 de noviembre de 1736. 
todos los que con religioso o autorizado documento hagan constar están empleados en las siembras y cultivos de los tabacos y rompen tierras para aumentar las cosechas".

Al mismo tiempo se aconsejó que los cosecheros de Santo Domingo quedaran exentos de determinados impuestos, cargas o gravámenes por espacio de diez o más años, justo "hasta que tomen todo su incremento las cosechas, cuyo ejemplar empezaron a disfrutar los pobladores de Sierra Morena". ${ }^{31}$ De igual modo se indicó la conveniencia de desarrollar también la siembra de tabaco en Puerto Rico - donde en 1785 se fundaba una factoría-, ${ }^{32}$ con la esperanza de obtener una hoja que si bien "no aventaja a la de Santo Domingo para la construcción de cigarros es igual en calidad y circunstancias". 33

En esta ocasión se planteaba además la posibilidad de que la producción de tabaco de las tres grandes Antillas juntas (Cuba, Puerto Rico y Santo Domingo) abasteciera a la Real Fábrica de Sevilla de la cantidad suficiente para cubrir toda la demanda de cigarros, "sin ser necesaria la hoja de Caracas, de la que solo se podrá usar en una necesidad urgente para misturarla con los tabacos de las tres islas, según lo pida la necesidad y el gusto de los que lo han de fumar. Este tabaco es demasiadamente suave y su gusto es un poco amargo, por cuyas dos circunstancias lo apetecen los holandeses, en los que está arraigado el vicio de no separar la pipa de la boca. Y como no les molesta la fortaleza, aman mejor esta clase de tabacos que el de otros parajes, y ordinariamente se proveen de él por la vía de Curaçao y es el que corre con el nombre de Barinas, de que en Cádiz se han hecho varios descaminos dirigidos a estas fábricas [de Sevilla]". ${ }^{34}$

Hubo incluso una petición al rey de los cosecheros de Santiago de un alza en el precio de venta de las distintas calidades de tabaco a la factoría que les igualara con el que regía para sus colegas cubanos; ${ }^{35}$ la aceptación

31 AGI, Santo Domingo, 1.055. Informe de José de Losada, cit. La cursiva es mía.

32 Véase Torres Ramírez, Bibiano: "D. Jaime O’Daly: propulsor del cultivo del tabaco en Puerto Rico", Revista del Instituto de Cultura Puertorriqueña, núm. 15, San Juan de Puerto Rico, 1962, págs. 49-52.

33 Las tierras más a propósito, se dice, serían las situadas próximas a San Juan para así facilitar el embarque de los cargamentos. De todas formas se aduce "la indiferencia de aquellos naturales [de Puerto Rico]" como causa de que no hubiesen prosperado convenientemente este y otros productos (algodón, añil, cacao, etc.) en la isla. Informe de José de Losada, cit.

34 Ibídem. La cursiva es mía.

35 AGI, Indiferente 1.745. Solano al rey. Santo Domingo, 24 de agosto de 1772. Consejo de Indias a Solano, marzo de 1773, en Expediente sobre la Administración de la renta del Tabaco (17631776). Moya Pons, Historia colonial, págs. 309-310. 
de esta demanda por parte de la Corona contribuyó a potenciar las expectativas depositadas en las explotaciones tabaqueras.

La animación suscitada por todas estas circunstancias favorables queda patente de este modo en una crónica ${ }^{36}$ de la época: "Por esta razón han tenido últimamente en las Fábricas de Sevilla una preferencia decidida los tabacos de Santo Domingo sobre los de La Habana para los cigarros. Nuestros andullos o garrotes de tabaco son los más apreciados de los franceses, para dar fragancia y cuerpo, con una tercera o cuarta parte de ellos, a su rapé. Esta introducción clandestina ha sido uno de los más fuertes comercios con que ha subsistido nuestra colonia en su mayor decadencia y que todavía da mucho jugo. Después que S.M. (que Dios guarde) ha puesto allí una Administración y toma algún número de quintales en rama, se han animado más los vecinos de Santiago, La Vega y Cotuí a su cultivo, han mejorado la calidad, no están sus pueblos tan miserables; y si se observan otras reglas y otra economía en la compra y conducciones, ganarían más los cultivadores y saldría a mejor precio para el Real Erario".

No menor euforia pudo causar el dictamen dado en 1773 por los peritos de Sevilla ante una partida de tabaco dominicano. ${ }^{37}$ Decía así: "nos ha parecido que de los 195 tercios de hojas de aquella isla que últimamente se recibieron en estas fábricas y reconocimos, los de superior calidad pueden estimarse equivalente a la hoja regular del partido de Santiago de Govea de la isla de La Habana [sic]; los de mediana calidad a la hoja del partido de Cuba largo y los de endeble a la hoja del partido de Bayamo Largo"

O la opinión que también sobre este particular ofreció el fiel de la fábrica hispalense, ${ }^{38}$ en cuya declaración se ponían de manifiesto algunas de las principales causas que habían mantenido estancado el desarrollo de la economía dominicana desde fines del siglo XVI (pérdida de importancia con respecto a las otras Grandes Antillas, escaso o nulo intercambio comercial con la Península, etc.). Así afirmaba con meridiana rotundidad que: "Lo cierto es que esta isla [Santo Domingo] ha dado los primeros tabacos que vinieron a España, y por haber tomado incremento el comercio de $\mathrm{La}$ Habana, pasó a decadencia el de esta por estar a trasmano y que las flotas ya no hacen arribo, ni refresco en ella, y sí en la de Puerto Rico. Pero continuando el que vengan las remesas, como las dos anteriores, y dándole a

36 Sánchez Valverde, Idea del valor, págs. 185-186.

37 AGI, Santo Domingo, 1.055. Informe sobre el tabaco de Santo Domingo. Sevilla, 17 de marzo de 1773 .

38 Ibídem. 
sus tabacos los beneficios que van en las prevenciones podrá desde luego servir para una y otra materia, así en la construcción de cigarros como en el polvo, respecto de venir manojos de hoja madura, anchas, de buen olor y suficiente cuerpo, con la fragancia que tienen los de los mejores partidos de la otra isla [Cuba]. Y, en fin, de una hoja se han hecho 40 cigarros, cosa no vista [nunca]".

A Santo Domingo podría aplicársele las mismas consideraciones que a Nueva España, es decir que la mayor parte de los plantíos de tabaco fueron "siempre pequeños y de que casi en su totalidad corrieran a cargo de modestos rancheros...[y] hasta cultivadores de subsistencia en superficies de una o dos hectáreas". ${ }^{39}$ Sin tener en cuenta la posibilidad de que en la Fábrica sevillana acabara exigiéndose una calidad determinada y un tipo concreto de hoja, un grupo considerable de hispanodominicanos se había dedicado a sembrar tabaco por doquier ante la tentadora perspectiva de las exportaciones a Sevilla.

Además de todo lo expuesto, la documentación relativa al cultivo, producción y comercialización del tabaco en Santo Domingo nos ofrece una serie de informaciones relativas a labores artesanales, fabricación de utensilios, compra de tejidos y profesiones especializadas todas ellas vinculadas al proceso tabaquero (seroneros, recueros, carpinteros, herreros, etcétera). Sin duda son una buena muestra del desarrollo económico generado por el negocio del tabaco, al tiempo que un magnífico testimonio del dinamismo que transmitió a gran parte de la población, como Sánchez Valverde refería, hasta conseguir devolverle a la zona española de la isla gran parte del valor que antaño había tenido. La importancia de estas actividades abre perspectivas muy halagüeñas en cuanto a que de la mayor parte de ellas apenas se habían proporcionado hasta ahora noticias al respecto, ni se habían mencionado en determinados trabajos de investigación, cuando es evidente su trascendencia para conocer mejor la vida económica de Santo Domingo. Veamos unas muestras.

Entre los gastos de la factoría de Santiago de los Caballeros, ${ }^{40}$ por ejemplo, llama la atención las siguientes partidas, además del papel, tinta y plumas para escribir:

39 Brading, David A.: Haciendas and ranchos in the Mexican Bajío: León, 1700-1860. Cambridge, 1978, pág. 151, citado por Céspedes, El tabaco, pág. 56.

40 AGI, Santo Domingo, 1.055. Cuenta y relación jurada dada por Francisco Espaillat, factor de la real renta de tabacos en Santiago, de los gastos causados desde uno de junio de 1789 hasta treinta de junio de 1790. 
- los sueldos de "los dos dependientes, escribiente y reconocedor de dicha factoría...a razón de quince pesos mensuales cada uno".

- los jornales de "un peón que sirve en la expresada factoría para el cuidado y aseo de los almacenes, a razón de tres reales diarios".

- el pago de los jornales a distintos grupos de peones, "a cuatro reales diarios a cada uno, por enseronar, cargar, almacenar y lo demás anejo al tabaco". ${ }^{4}$

- el alquiler de las casas "factorías y almacenes en que se depositan los tabacos de S.M.", a razón de cuarenta pesos mensuales.

- la compra de mil quinientas sesenta y ocho arrobas de tabaco de "tienda", tres mil novecientas doce de tabaco "rescogido" y cuatro mil quinientas veinte de tabaco de "libra", a dieciocho, dieciséis y doce reales la arroba respectivamente.

- la adquisición de dos mil quinientos serones para "empacar y remitir los expresados tabacos [a Santo Domingo]", así como de quinientos ochenta y nueve serones "averiados en el manejo de la conducción de las haciendas de los labradores a esta factoría", a cuatro reales el par. Por el volumen mencionado debió existir, no cabe duda, un grupo de artesanos dedicados a la fabricación de estas espuertas, pues estamos ante cantidades realmente importantes.

- las cargas de yaguas "gastadas en el abrigo y empaque del tabaco, a razón de dos reales cada carga". ${ }^{42}$

- las siete mil "y más varas" de cordel de cabuya para coser las bocas de los serones en que se acondicionó el tabaco". ${ }^{43}$

- los naipes ${ }^{44}$ comprados "para poner a cada serón la cantidad, calidad y peso de tabaco que contiene, partido donde se cosechó y nombre del labrador", además de papel de escribir y otros gastos de escritorio.

- la docena y media de tablas de palma "gastadas en la recomposición de los tablados sobre los que se colocan los tercios de tabaco en los almacenes para precaver la humedad, a dos pesos docena".

41 La mayor parte de estas partidas se rebajan en el importe consignado "por haber comprendido los jornales correspondientes a días de fiesta que hubo en dicho tiempo, en que no se pudo trabajar".

42 La yagua es un tejido fibroso que rodea la parte superior del tronco de la palma real y que entonces servía para envolver tabaco en rama.

43 La cabuya es una cuerda obtenida de la pita.

44 En este contexto se entiende "naipe" como la cartulina o el cartón en blanco "cortado a la proporción de la vigésima cuarta parte de un pliego común", según definición del Diccionario de Autoridades. 
Entre los conceptos que por ingresos o gastos quedan registrados en las cuentas de la factoría de Santo Domingo podemos destacar los siguientes:

- la venta de "porción de serones que han resultado útiles de los que se han servido para transportar los tabacos desde la ciudad de Santiago a esta [Santo Domingo], y que por lo que padecen en el tránsito no quedan en estado de volver a servir para el mismo uso, y por tanto se benefician al público los menos maltratados"

- pago al carpintero Juan Simono "por componer y acondicionar diez cajones en que se pusieron catorce mil pesos" para su envío a la ciudad de Santiago "para entregar a aquel factor, D. Francisco Espaillat, al fin de ocurrir con ellos a la compra de tabacos de S.M.". Así como al también carpintero Martín Carrasco "por el trabajo hecho en cinco piezas de husillos y tuercas" y al herrero Juan Valerio "por la composición de varias piezas de hierro", todo para las prensas.

- los "fletes de tierra" ocasionados por el transporte de los tercios de tabaco remitidos por la factoría de Santiago, "en diferentes partidas, con diversos recueros" ${ }^{45}$ Este es un tema del que mereceríamos conocer más, pues nos daría la pauta de todo un perfecto sistema de arriería para el transporte de mercancías al igual que sucedía en el continente. ${ }^{46}$

- ocho cargas de majagua "gastadas en fajar y atrincar los tercios de tabaco al tiempo de aprensarlo para su empaque". ${ }^{47}$

- adquisición de palos de capá ${ }^{48}$ para "el reparo y composición de las prensas"

- pago a la cuadrilla de borriqueros cargadores por la conducción de los tercios de tabaco "desde los Reales Almacenes de esta ciudad al muelle del puerto, o para cuando se verifique su embarque a los reinos de España, a razón de un cuartillo de real por cada tercio".

\footnotetext{
45 El recuero es el arriero a cuyo cargo está la recua. Del apéndice final que incluimos en este trabajo se pueden deducir quienes eran éstos. La cursiva es mía.

46 Véase Serrera Contreras, Ramón: Tráfico terrestre y red vial en las Indias españolas. Madrid, 1992, págs. 222 y siguientes.

47 La majagua es un árbol americano de las malváceas, de cuya corteza se hacen sogas de larga duración.

48 Madera de un árbol propio de las Antillas, parecido al roble, que suele utilizarse también en la construcción naval. Destacan dos variedades, el capá colorado y el capá prieto, éste de madera especialmente fuerte.
} 
- la compra de distintas cantidades de "varas de Bramante crudo a razón de tres y medio reales de plata cada vara" para el empaque de tabacos. ${ }^{49}$

- setenta y cinco madejas de hilo acarreto para coser los tercios de tabaco, además de arroba y media de hilo de cáñamo gastada en el empaque y 56 agujas "que se compraron para coser los fardos de tabaco".

- jabón para untar los husillos de las prensas. ${ }^{50}$ Con fines idénticos se adquirieron velas de sebo de Flandes.

- papel, tinta, plumas y "demás gastos de escritorio gastados en el uso de la factoría", al igual que la tinta adquirida para marcar los tercios de tabaco.

- los jornales de los peones "que trabajaron, a más del negro esclavo de dicha factoría, en aprensar, coser y otras faenas, a razón de cuatro reales diarios cada uno".

- el sueldo correspondiente al maestro enfardelador, don Francisco Tamayo. ${ }^{51}$

- los diarios "suministrados al negro Miguel, esclavo de S.M., empleado en el servicio de dicha factoría", a razón de un real por día, ${ }^{52}$ además del importe de su vestuario.

El apéndice documental que acompaña al presente artículo forma parte del expediente donde se contienen las cuentas pormenorizadas de los ingresos y gastos causados por las dos factorías de tabaco de la parte espanola de la isla. Consiste en 105 asientos contables - el primero de 22 de febrero de 1790 y el último de 30 de julio del mismo año-, donde se relacionan los envíos de tabaco desde la factoría de Santiago a la de Santo Domingo, los "fletes de tierra" abonados "en plata del cuño mexicano" por el transporte de los tercios y el nombre de las personas a quienes se les paga, que son esos recueros a los que antes hemos aludido.

En general, todos los asientos son del mismo tenor. Transcribimos íntegramente el primero de ellos a modo de ejemplo, mientras que para el resto hemos preferido suplir las expresiones que son comunes a todos ellos

49 Las partidas señalan compras de 3.165, 1.133 y 362 varas castellanas a Pedro de Echegarreta, Pedro Gatell y Pedro Petreña, respectivamente.

50 El husillo es un tornillo de hierro o madera que hay en las prensas y otras máquinas.

51 Enfardar o enfardelar significar hacer o arreglar fardos, embalar. La cursiva es mía.

52 Diario es el valor o gasto correspondiente a cada día. 
por otras locuciones más cortas con el fin de aligerar el texto. Así, la expresión "He recibido del señor D. Andrés de Lecanda, factor principal del real ramo de tabacos" se sustituye siempre por un Ídem; del mismo modo las frases "desde la real factoría de la ciudad de Santiago a esta factoría principal [o a esta capital]" y "que a razón de tres pesos y dos reales ha importado dicha cantidad" han sido reemplazadas por puntos suspensivos.

Señalemos como datos interesantes o curiosos que en solo cuatro de los asientos se alude expresamente a la calidad del tabaco transportado. En uno de ellos se cita la "calidad rescogido", mientras en los otros tres se alude a la "calidad de libra", es decir las de segunda y tercera categoría respectivamente según la clasificación establecida para las remesas del producto llegadas a Sevilla. ${ }^{53}$ Quizás podríamos suponer que los restantes envíos estarían compuestos por tabaco de "tienda", el más apreciado por la Real Fábrica hispalense para la confección de cigarros.

Un 83\% de los recueros utilizan a otra persona o a un compañero para rubricar los recibos del cobro de los fletes "por no saber firmar", al tiempo que entre ellos aparecen sujetos con el mismo apellido que probablemente indique una actividad familiar común (Juan Antonio Estrada y Francisco Estrada; Ildefonso Apolinario y Diego Apolinario, etcétera). Y no dejemos de mencionar que en ocho ocasiones son esclavos quienes conducen el tabaco y aparecen identificados por sus propietarios, a tres de los cuales se les antepone el título de "don" (Francisco Jiménez, Melchor Guriel y Dionisio de Moya) quizás por tratarse de personas distinguidas de Santiago de los Caballeros o incluso cosecheros.

53 Véase Gutiérrez Escudero, "El tabaco en Santo Domingo”, pág. 132. 



\section{Apéndice documental}

\section{CUENTA Y RELACIÓN GENERAL DE LOS INGRESOS Y GASTOS PRESENTADOS POR EL FACTOR PRINCIPAL DEL REAL RAMO DE TABACOS DE LA CIUDAD DE SANTO DOMINGO ${ }^{54}$ (EXTRACTO)}

He recibido del señor D. Andrés de Lecanda, Factor principal del Real Ramo de tabacos la cantidad de cincuenta y dos pesos en plata del cuño mexicano, por dieciséis quintales de tabaco que desde la Real Factoría de la ciudad de Santiago he conducido a esta principal, a razón de tres pesos y dos reales por cada quintal. Santo Domingo, veintidós de febrero de mil setecientos noventa. A ruego de Damián Esteban por no saber firmar, Manuel María Loyé.

Ídem, la cantidad de ciento y cuatro pesos de plata del cuño mexicano, por treinta y dos quintales de tabaco... Santo Domingo, veintidós de febrero de mil setecientos noventa. A ruego de Juan de los Reyes por no saber firmar, Manuel María Loyé

Ídem, la cantidad de ciento veintitrés pesos y cuatro reales, en plata del cuño mexicano, por treinta y ocho quintales de tabaco... Santo Domingo, veinticinco de febrero de mil setecientos noventa. A ruego de Andrés Agama por no saber firmar, Juan Antonio Estrada

Ídem, la cantidad de sesenta y cinco pesos en plata del cuño mexicano, por veinte quintales de tabaco... Santo Domingo, veinticinco de febrero de mil setecientos noventa. A ruego de Damián de la Concepción, Francisco Estrada

Ídem, la cantidad de noventa y un pesos en plata del cuño mexicano, por veintiocho quintales de tabaco... Santo Domingo, veinticinco de febrero de mil setecientos noventa. Ildefonso Apolinario.

Ídem, la cantidad de noventa y siete pesos y cuatro reales en plata, del cuño mexicano, por treinta quintales de tabaco... Santo Domingo, veinticinco de febrero de mil setecientos noventa. A ruego de Esteban Gómez, Francisco Estrada

Ídem, la cantidad de cincuenta y ocho pesos y cuatro reales en plata del cuño mexicano, por la conducción de dieciocho quintales de tabaco... Santo Domingo, febrero, veintiséis de mil setecientos noventa. A ruego de Antonio, esclavo de Miguel del Castillo, Martín del Castillo.

Ídem, la cantidad de setenta y un pesos y cuatro reales en plata del cuño mexicano, por la conducción de los fletes... de veintidós quintales de tabaco... Santo Domingo, veintiséis de febrero de mil setecientos noventa. Fulgencio de la Rosa.

54 AGI, Santo Domingo, 1.055. 
Ídem, la cantidad de ciento sesenta y dos pesos y cuatro reales en plata, del cuño mexicano, por la conducción de los fletes... de cincuenta quintales de tabaco... Santo Domingo, veintisiete de febrero de mil setecientos noventa. Manuel González. Ídem, la cantidad de ciento treinta y seis pesos y cuatro reales en plata del cuño mexicano, por la conducción de fletes...[de cuarenta y dos quintales de tabaco]... Santo Domingo, primero de marzo de mil setecientos noventa. A ruego de Tomás Muñoz, Gregorio Félix

Ídem, la cantidad de sesenta y cinco pesos en plata del cuño mexicano, como apoderado de D. Baltasar Núñez, por veinte quintales de tabaco que condujo Santiago, esclavo del dicho... Santo Domingo, primero de marzo de mil setecientos noventa. Juan Pablo de la Mota.

Ídem, la cantidad de cincuenta y dos pesos en plata del cuño mexicano, por dieciséis quintales de tabaco que he conducido... Santo Domingo, primero de marzo de mil setecientos noventa. A ruego de José, esclavo de Juan Eduardo, por no saber firmar, Manuel María Loyé.

Ídem, la cantidad de ciento cuatro pesos en plata del cuño mexicano, por la conducción de treinta y dos quintales de tabaco... Santo Domingo, dos de marzo de mil setecientos noventa. A ruego de Juan de Burgos, Domingo Márquez.

Ídem, la cantidad de cuarenta y cinco pesos y cuatro reales en plata del cuño mexicano, por la conducción de catorce quintales de tabaco... Santo Domingo, dos de marzo de mil setecientos noventa. A ruego de Carlos de Rojas, Domingo Márquez.

Ídem, la cantidad de sesenta y ocho pesos en plata del cuño mexicano, por la conducción de veinticuatro quintales de tabaco... Santo Domingo, dos de marzo de mil setecientos noventa. A ruego de Mauricio Acevedo, Francisco Estrada.

Ídem, la cantidad de ciento cuatro pesos en plata del cuño mexicano, por la conducción de treinta y dos quintales de tabaco... Santo Domingo, tres de marzo de mil setecientos noventa. A ruego Manuel de Paula, Pedro Navarro.

Ídem, la cantidad de ciento treinta y seis pesos y cuatro reales en plata del cuño mexicano, por la conducción de cuarenta y dos quintales de tabaco, calidad de Libras... Santo Domingo, tres de marzo de mil setecientos noventa. A ruego de José Antonio, Pedro Navarro.

Ídem, la cantidad de diecinueve pesos y cuatro reales en plata de cuño mexicano, por la conducción de seis quintales de tabaco... Santo Domingo, cuatro de marzo de mil setecientos noventa. A ruego de Agustín de Acosta, Francisco Estrada.

Ídem, la cantidad de cincuenta y ocho pesos y cuatro reales en plata del cuño mexicano, por la conducción de dieciocho quintales de tabaco que desde la ciudad de Santiago a esta capital he conducido... Santo Domingo, seis de marzo de mil setecientos noventa. A ruego de Alejo de Tejada, Calixto Antonio.

Ídem, la cantidad de setenta y ocho pesos en plata del cuño mexicano, por la conducción de veinticuatro quintales de tabaco... Santo Domingo, seis de marzo de mil setecientos noventa. A ruego de Bonifacio Jorquina, Manuel María Loyé. 
Ídem, la cantidad de setenta y un pesos y cuatro reales en plata al cuño mexicano, por la conducción de veintidós quintales de tabaco... Santo Domingo, nueve de marzo de mil setecientos noventa. A ruego de Francisco Rodríguez, Pedro Navarro.

Ídem, la cantidad de veintiséis pesos en plata de cuño mexicano, por la conducción de ocho quintales de tabaco... Santo Domingo, diez de marzo de mil setecientos noventa. A ruego de Manuel Santiago, Pedro Navarro.

Ídem, la cantidad de treinta y nueve pesos en plata de cuño mexicano, por la conducción de doce quintales de tabaco... Santo Domingo, diez de marzo de mil setecientos noventa. A ruego de Manuel Suárez, Pedro Navarro.

Ídem, la cantidad de noventa y siete pesos del cuño mexicano, por la conducción de treinta quintales de tabacos... Santo Domingo, diez de marzo de mil setecientos noventa. A ruego de Manuel Julián Bretón, Pedro Navarro.

Ídem, la cantidad de cuarenta y cinco pesos y cuatro reales en plata del cuño mexicano, por la conducción de catorce quintales de tabaco, de la calidad de Libras... Santo Domingo, once de marzo de mil setecientos noventa. A ruego de Valentín, esclavo de D. Francisco Jiménez, Pedro Navarro.

Ídem, la cantidad de sesenta y cinco pesos en plata del cuño mexicano, por la conducción de veinte quintales de tabacos... Santo Domingo, once de marzo de mil setecientos noventa. A ruego de Lorenzo Rodríguez, Pedro Navarro.

Ídem, la cantidad de noventa y un pesos en plata del cuño mexicano, por la conducción de veintiocho quintales de tabaco... Santo Domingo, once de marzo de mil setecientos noventa. A ruego de Lorenzo Rodríguez, Pedro Navarro.

Ídem, la cantidad de sesenta y cinco pesos en plata del cuño mexicano, por la conducción de veinte quintales de tabaco... Santo Domingo, trece de marzo de mil setecientos noventa. A ruego de José Ramos, Manuel María Loyé.

Ídem, la cantidad de cincuenta y dos pesos en plata del cuño mexicano, por la conducción de dieciséis quintales de tabaco... Santo Domingo, trece de marzo de mil setecientos noventa. A ruego de Tomás Francisco, Manuel María Loyé.

Ídem, la cantidad de treinta y nueve pesos en plata del cuño mexicano, por la conducción de doce quintales de tabaco... Santo Domingo, quince de marzo de mil setecientos noventa. A ruego de Gabriel, esclavo de Félix de Ortega, Manuel María Loyé.

Ídem, la cantidad de setenta y ocho pesos en plata del cuño mexicano, por la conducción de veinticuatro quintales de tabaco... Santo Domingo, quince de marzo de mil setecientos noventa. A ruego de Juan Martín, Ignacio Mejía.

Ídem, la cantidad de cincuenta y dos pesos en plata de cuño mexicano, por la conducción de dieciséis quintales de tabaco... Santo Domingo, diecisiete de marzo de mil setecientos noventa. A ruego de Pedro Rodríguez, Pedro Navarro.

Ídem, la cantidad de treinta y nueve pesos en plata del cuño mexicano, por los fletes de doce quintales de tabaco que de cuenta de S.M. he conducido... Santo Domingo, diecisiete de marzo de mil setecientos noventa. A ruego de Manuel Hernández, Pedro Navarro. 
Ídem, la cantidad de setenta y un pesos y cuatro reales en plata del cuño mexicano, por los fletes de veintidós quintales de tabaco, que de cuenta de S.M. he conducido... Santo Domingo, dieciocho de marzo de mil setecientos noventa. Félix Reinoso.

Ídem, la cantidad de treinta y nueve pesos en plata del cuño mexicano, por los fletes de doce quintales de tabaco, que de cuenta de S.M. he conducido... Santo Domingo, dieciocho de marzo de mil setecientos noventa. A ruego de Dionisio Martín, Romualdo Arránz.

Ídem, la cantidad de ciento treinta y tres pesos, cinco y medio reales en plata del cuño mexicano, los que habían de ser ciento treinta y seis pesos y cuatro reales, de los que se rebajan dos pesos, seis y medio reales por haber faltado una arroba de tabaco de los cuarenta y dos quintales, que conduje de cuenta de S.M... Santo Domingo, veinte de marzo de mil setecientos noventa. A ruego de Gaspar del Rosario, Francisco Estrada.

Ídem, la cantidad de treinta y nueve pesos en plata del cuño mexicano, por los fletes de doce quintales de tabaco que de cuenta de S.M. he conducido... Santo Domingo, veintidós de marzo de mil setecientos noventa. A ruego de José Martín, Manuel María Loyé.

Ídem, la cantidad de treinta y nueve pesos en plata del cuño mexicano, por los fletes de doce quintales de tabaco, que de cuenta de S.M. he conducido... Santo Domingo, veintitrés de marzo de mil setecientos noventa. A ruego de José Gómez, Francisco Estrada.

Ídem, la cantidad de cuarenta y cinco pesos y cuatro reales en plata del cuño mexicano, por la conducción de catorce quintales de tabaco, que desde la ciudad de Santiago he conducido de cuenta de S.M... Santo Domingo, veinticuatro de marzo de mil setecientos noventa. A ruego de Agustín Arcacio, Francisco Superanis.

Ídem, la cantidad de treinta y dos pesos y cuatro reales en plata del cuño mexicano, por los fletes de diez quintales de tabaco que de cuenta de S.M... Santo Domingo, veinticuatro de marzo de mil setecientos noventa. A ruego de José Espinar, Francisco Estrada.

Ídem, la cantidad de setenta y ocho pesos en plata del cuño mexicano, por los fletes de veinticuatro quintales de tabaco, que de cuenta de S.M. he conducido... Santo Domingo, veintiséis de marzo de mil setecientos noventa. A ruego de Benito Javier, Francisco Estrada.

Ídem, la cantidad de ciento setenta y cinco pesos, y cuatro reales en plata del cuño mexicano, por los fletes de cincuenta y cuatro quintales de tabaco, que de cuenta de S.M. he conducido... Santo Domingo, treinta de marzo de mil setecientos noventa. A ruego de Juan Rodríguez, Francisco Estrada.

Ídem, la cantidad de setenta y un pesos y cuatro reales del cuño mexicano, por los fletes de veintidós quintales de tabaco que de cuenta de S.M... he conducido... Santo Domingo, treinta y uno de marzo de mil setecientos noventa. Miguel de Jesús. 
Ídem, la cantidad de noventa y un pesos en plata del cuño mexicano, por los fletes de veintiocho quintales de tabaco, que de cuenta de S.M. he conducido... Santo Domingo, treinta y uno de marzo de mil setecientos noventa. A ruego de Pedro del Castillo, Francisco Estrada.

Ídem, la cantidad de cuarenta y cinco pesos y cuatro reales en plata del cuño mexicano, por los fletes de catorce quintales de tabacos de la calidad de Libras, lo que de cuenta de S.M. he conducido... Santo Domingo, treinta y uno de marzo de mil setecientos noventa. A ruego de Vicente Juano, Gabriel de los Santos.

Ídem, la cantidad de ciento cuarenta y nueve pesos y cuatro reales en plata del cuño mexicano, por los fletes de cuarenta y seis quintales de tabaco que de cuenta de S.M. he conducido... Santo Domingo, treinta y uno de marzo de mil setecientos noventa. A ruego de Juan Martín, Gabriel de los Santos.

Ídem, la cantidad de ciento treinta y seis pesos y cuatro reales en plata del cuño mexicano, por los fletes de cuarenta y dos quintales de tabaco que de cuenta de S.M. he conducido... Santo Domingo, tres de abril de mil setecientos noventa. A ruego de Manuel Jiménez, Manuel María Loyé.

Ídem, la cantidad de ciento noventa y cinco pesos en plata del cuño mexicano, por los fletes de sesenta quintales de tabaco que de cuenta de S.M., he conducido... Santo Domingo, seis de abril de mil setecientos noventa. A ruego de José, esclavo de D. Melchor Guriel, Tomás Rodríguez.

Ídem, la cantidad de ochenta y cuatro pesos y cuatro reales en plata, del cuño mexicano, por los fletes de veintiséis quintales de tabaco, que de cuenta de S.M. he conducido... Santo Domingo, doce de abril de mil setecientos noventa. A ruego de Mateo del Rosario, José de Ribera.

Ídem, la cantidad de cuarenta y cinco pesos y cuatro reales en plata del cuño mexicano, por los fletes de catorce quintales de tabaco que de cuenta de S.M., he conducido... Santo Domingo, veinte de abril de mil setecientos noventa. A ruego de Andrés Agama, Tomás Rodríguez.

Ídem, la cantidad de ciento sesenta y nueve pesos en plata del cuño mexicano, correspondientes a los fletes de cincuenta y dos quintales de tabaco, que de cuenta de S.M. he conducido... Santo Domingo, veintiuno de abril de mil setecientos noventa. A ruego de Damián de los Reyes, Tomás Rodríguez.

Ídem, la cantidad de treinta y nueve pesos en plata del cuño mexicano, pertenecientes a los fletes que me corresponden por la conducción de doce quintales de tabaco... todo de cuenta de S.M... Santo Domingo, veintidós de abril de mil setecientos noventa. A ruego de Paulino del Rosario, José Ribera.

Ídem, la cantidad de sesenta y cinco pesos en plata del cuño mexicano, pertenecientes a los fletes de veinte quintales de tabaco, que he conducido de cuenta de S.M... Santo Domingo, veintidós de abril de mil setecientos noventa. A ruego de Bernardo Durán, Tomás Rodríguez.

Ídem, la cantidad de ciento veintitrés pesos y cuatro reales en plata del cuño mexicano, que me corresponden por los fletes de la conducción de diecinueve car- 
gas de tabaco de cuenta de S.M... que a razón de tres pesos y dos reales o seis pesos y medio cada carga... Santo Domingo, veintitrés de abril de mil setecientos noventa. José de Ribera.

Ídem, la cantidad de ciento cuarenta y tres pesos en plata del cuño mexicano, por los fletes de la conducción de cuarenta y cuatro quintales de tabaco de cuenta de S.M... Santo Domingo, veintitrés de abril de mil setecientos noventa. José de Ribera.

Ídem, la cantidad de setenta y ocho pesos en plata del cuño mexicano, por la conducción de veinticuatro quintales de tabaco de cuenta de S.M... Santo Domingo, veinticuatro de abril de mil setecientos noventa. A ruego de Manuel Julián Bretón, Juan Isidro.

Ídem, la cantidad de ciento cuatro pesos en plata del cuño mexicano, por la conducción de treinta y dos quintales de tabaco... Santo Domingo, veintiséis de abril de mil setecientos noventa. A ruego de Manuel Polanco, Francisco Estrada.

Ídem, la cantidad de sesenta y cinco pesos en plata del cuño mexicano, por la conducción de veinte quintales de tabaco, de cuenta de S.M... Santo Domingo, veintisiete de abril de mil setecientos noventa. A ruego de Diego Martín, Francisco Estrada.

Ídem, la cantidad de ciento diecisiete pesos en plata del cuño mexicano, por los fletes que me corresponden por haber conducido de cuenta de S.M. treinta y seis quintales de tabaco... Santo Domingo, veintisiete de abril de mil setecientos noventa. A ruego de Manuel López, Francisco Estrada.

Ídem, la cantidad de setenta y un pesos y cuatro reales en plata del cuño mexicano, por la conducción de veintidós quintales de tabaco... Santo Domingo, veintinueve de abril de mil setecientos noventa. Juan Mejía.

Ídem, la cantidad de cincuenta y dos pesos en plata, del cuño mexicano, por los fletes que me pertenecen por haber conducido... dieciséis quintales de tabaco... Santo Domingo, cuatro de mayo de mil setecientos noventa. A ruego de Dionisio del Rosario, Tomás Rodríguez.

Ídem, la cantidad de setenta y ocho pesos en plata del cuño mexicano, por los fletes que me corresponden por haber conducido... veinticuatro quintales de tabaco... Santo Domingo, cuatro de mayo de mil setecientos noventa. A ruego de Pedro del Amparo, Tomás Rodríguez.

Ídem, la cantidad de setenta y un pesos y cuatro reales en plata, del cuño mexicano, los mismos que me corresponden por haber conducido... veintidós quintales de tabaco... Santo Domingo, cinco de mayo de mil setecientos noventa. A ruego de Agustín de Acosta, Sebastián Sánchez.

Ídem, la cantidad de sesenta y cinco pesos en plata del cuño mexicano, los mismos que me corresponden por los veinte quintales de tabaco... Santo Domingo, ocho de mayo de mil setecientos noventa. A ruego de Gregorio Esgueva, Manuel María Loyé. 
Ídem, la cantidad de ciento cuarenta y tres pesos en plata del cuño mexicano, los mismos que me pertenecen por haber conducido... cuarenta y cuatro quintales de tabaco... Santo Domingo, nueve de mayo de mil setecientos noventa. A ruego de Bonifacio Jolquiño, Tomás Rodríguez.

Ídem, la cantidad de sesenta y cinco pesos, pertenecientes a veinte quintales de tabaco, que de cuenta de S.M. he conducido... Santo Domingo, nueve de mayo de mil setecientos noventa. A ruego de Carlos Cordero, Manuel de la Rosa Bocanegra.

Ídem, la cantidad de setenta y ocho pesos en plata del cuño mexicano, por la conducción de veinticuatro quintales de tabaco... Santo Domingo, quince de mayo de mil setecientos noventa. A ruego de Bruno Sánchez, Francisco Estrada.

Ídem, la cantidad de treinta y dos pesos y cuatro reales en plata del cuño mexicano, por la conducción de diez quintales de tabaco... Santo Domingo, quince de mayo de mil setecientos noventa. A ruego de Eusebio López, Francisco Estrada.

Ídem, la cantidad de veintiséis pesos en plata del cuño mexicano, por la conducción de ocho quintales de tabaco... Santo Domingo, quince de mayo de mil setecientos noventa. A ruego de José Martínez, Francisco Estrada.

Ídem, la cantidad de treinta y dos pesos y cuatro reales en plata del cuño mexicano, los mismos que me corresponden por haber conducido de cuenta de S.M. diez quintales de tabaco... Santo Domingo, diecisiete de mayo de mil setecientos noventa. A ruego de Félix Guzmán, José de Ribera.

Ídem, la cantidad de sesenta y cinco pesos en plata del cuño mexicano, por haber conducido veinte quintales de tabaco... Santo Domingo, veintitrés de mayo de mil setecientos noventa. A ruego de Ramón Bueno, José María Rodríguez.

Ídem, la cantidad de ciento treinta pesos en plata del cuño mexicano, por la conducción de cuarenta quintales de tabaco... Santo Domingo, veintinueve de mayo de mil setecientos noventa. Manuel de los Santos.

Ídem, la cantidad de cincuenta y ocho pesos y cuatro reales en plata del cuño mexicano, por haber conducido desde la ciudad de Santiago a esta capital, dieciocho quintales de tabaco... Santo Domingo, treinta y uno de mayo de mil setecientos noventa. Francisco Rodríguez.

Ídem, la cantidad de sesenta y cuatro pesos y cuatro reales en plata, por la conducción de veintiséis quintales de tabaco de calidad Rescogido... Santo Domingo, seis de junio de mil setecientos noventa. Diego Apolinario.

Ídem, la cantidad de ciento diez pesos y cuatro reales, por haber conducido treinta y cuatro quintales de tabaco... Santo Domingo, nueve de junio de mil setecientos noventa. A ruego de Valentín Hidalgo, José María Rodríguez.

Ídem, la cantidad de doscientos ocho pesos en plata fuerte, por haber conducido... sesenta y cuatro quintales de tabaco... Santo Domingo, dieciséis de junio de mil setecientos noventa. A ruego de José, esclavo de D. Melchor Guriel, Nicolás de Mueces. 
Ídem, la cantidad de cincuenta y dos pesos, por haber conducido... dieciséis quintales de tabaco... Santo Domingo, diecisiete de junio de mil setecientos noventa. José Suárez.

Ídem, la cantidad de treinta y dos pesos y cuatro reales, por haber conducido... diez quintales de tabacos... Santo Domingo, dieciocho de junio de mil setecientos noventa. A ruego de Damián Esteban, Manuel Reyes.

Ídem, la cantidad de cincuenta y ocho pesos y cuatro reales en plata del cuño mexicano, por haber conducido... dieciocho quintales de tabaco... Santo Domingo, veintidós de junio de mil setecientos noventa. A ruego de Mauricio Acevedo, Francisco Hernández.

Ídem, la cantidad de cincuenta y dos pesos, por la conducción de dieciséis quintales de tabaco... Santo Domingo, y junio veintitrés, de mil setecientos noventa. A ruego de Pedro, esclavo de D. Dionisio de Moya, Gaspar Gómez.

Ídem, la cantidad de noventa y un pesos por la conducción de veintiocho quintales de tabaco... Santo Domingo, veintitrés de junio de mil setecientos noventa. Ildefonso Apolinario.

Ídem, la cantidad de cuarenta y cinco pesos y cuatro reales, por haber conducido catorce quintales de tabaco... Santo Domingo, veintitrés de Junio de mil setecientos noventa. A ruego de Victoriano Jacques, Ildefonso Apolinario.

Ídem, la cantidad de noventa y un pesos por la conducción de veintiocho quintales de tabaco... Santo Domingo, veintitrés de junio de mil setecientos noventa. A ruego de Miguel Pascual, Juan Antonio Estrada.

Ídem, la cantidad de treinta y nueve pesos por la conducción de doce quintales de tabaco, que he conducido... Santo Domingo, y junio, veintitrés de mil setecientos noventa. A ruego de Francisco Pérez, Juan Antonio Estrada.

Ídem, la cantidad de treinta y nueve pesos por haber conducido, desde la ciudad de Santiago a esta capital, doce quintales de tabacos... Santo Domingo, veintitrés de junio de mil setecientos noventa. A ruego de Agustín Paulino, Juan Antonio Estrada.

Ídem, la cantidad de setenta y ocho pesos por el flete de veinticuatro quintales de tabaco, que he conducido... Santo Domingo, veintitrés de junio de mil setecientos noventa. A ruego de Esteban Gómez, Juan Antonio Estrada.

Ídem, la cantidad de cincuenta y dos pesos, por haber conducido dieciséis quintales de tabacos... Santo Domingo, veintitrés de junio de mil setecientos noventa. A ruego de Juan Eduardo, Juan Antonio Estrada.

Ídem, la cantidad de noventa y un pesos, por la conducción de veintiocho quintales de tabaco... Santo Domingo, veintitrés de junio de mil setecientos noventa. A ruego de Manuel de Lora, Félix Núñez.

Ídem, la cantidad de veintiséis pesos, por haber conducido ocho quintales de tabaco... Santo Domingo, veintiséis de junio de mil setecientos noventa. A ruego de Félix Jerez, Ignacio Cáceres. 
Ídem, la cantidad de ciento cincuenta y seis pesos, por la conducción de cuarenta y ocho quintales de tabaco... Santo Domingo, veintiséis de junio, de mil setecientos noventa. A ruego de Manuel Jiménez, Tomás Rodríguez.

Ídem, la cantidad de sesenta y cinco pesos, por haber conducido desde la ciudad de Santiago a esta capital, veinte quintales de tabaco... Santo Domingo, veintiocho de junio de mil setecientos noventa. Calixto Antonio.

Ídem, la cantidad de treinta y dos pesos y cuatro reales, por la conducción de diez quintales de tabacos... Santo Domingo, veintiocho de junio de mil setecientos noventa. A ruego de Juan de la Antigua, José Ribera.

Ídem, la cantidad de ochenta y cuatro pesos y cuatro reales, por la conducción de veintiséis quintales de tabacos... Santo Domingo, treinta de junio de mil setecientos noventa. A ruego de Dionisio Martín, José Ribera.

Ídem, la cantidad de ciento cuatro pesos, por la conducción de treinta y dos quintales de tabaco... Santo Domingo, treinta de junio de mil setecientos noventa. A ruego de Antonio del Rosario, José Ribera.

Ídem, la cantidad de cuarenta y cinco pesos y cuatro reales, por la conducción de catorce quintales de tabaco... Santo Domingo, treinta de junio de mil setecientos noventa. A ruego de Juan de Burgos, Tomás Rodríguez.

Ídem, la cantidad de sesenta y cinco pesos, por la conducción de veinte quintales de tabaco... Santo Domingo, treinta de junio de mil setecientos noventa. A ruego de José Martín, José Ribera.

Ídem, la cantidad de setenta y un pesos y cuatro reales, por haber conducido... veintidós quintales de tabaco... Santo Domingo, primero de julio de mil setecientos noventa. Fulgencio de la Rosa.

Ídem, la cantidad de setenta y ocho pesos, por haber conducido... veinticuatro quintales de tabaco... Santo Domingo, primero de julio de mil setecientos noventa. A ruego de Juan Rodríguez, José Ribera.

Ídem, la cantidad de noventa y un peso por la conducción de veintiocho quintales de tabaco... Santo Domingo, primero de julio de mil setecientos noventa. A ruego de Andrés Olivo, José Ribera.

Ídem, la cantidad de diecinueve pesos y cuatro reales, por la conducción de seis quintales de tabacos... Santo Domingo, primero de julio de mil setecientos noventa. A ruego de Lucas del Hierro, José Ribera.

Ídem, la cantidad de ciento diez pesos y cuatro reales, por haber conducido... treinta y cuatro quintales de tabaco... Santo Domingo, primero de julio de mil setecientos noventa. A ruego de Isidro de Peña, José Ribera.

Ídem, la cantidad de treinta y nueve pesos por la conducción de doce quintales de tabaco... Santo Domingo, seis de julio de mil setecientos noventa. A ruego de Juan Hurtarter, José Ribera.

Ídem, la cantidad de cuarenta y cinco pesos y cuatro reales, por haber conducido... catorce quintales de tabaco... Santo Domingo, ocho de julio, de mil setecientos noventa. A ruego de Pedro Nolasco, José Ribera. 
Ídem, la cantidad de cincuenta y dos pesos, por haber conducido... dieciséis quintales de tabaco... Santo Domingo, ocho de julio de mil setecientos noventa. A ruego de Gaspar de los Reyes, José Ribera.

Ídem, la cantidad de ciento cuatro pesos, por haber conducido desde la ciudad de Santiago a esta capital treinta y dos quintales de tabaco, que a razón de tres pesos y dos reales cada uno ha importado dicha cantidad. Santo Domingo, ocho de julio de mil setecientos noventa. A ruego de Manuel Cordero, José Ribera.

Suma todo ocho mil ciento veintidós pesos, uno y medio reales, de los dos mil quinientos quintales de tabaco. Es conforme al cuaderno original de su contenido, el que queda archivado en la oficina de mi cargo, y al que me remito. Santo Domingo, treinta de julio de mil setecientos noventa. Andrés de Lecanda. 